\title{
Presentation and management of giant fibroid uterus in an adolescent girl
}

This article was published in the following Dove Press journal:

Open Access Surgery

12 March 2010

Number of times this article has been viewed

\section{Tanweer Karim \\ Kundan Patil \\ Anuradha Panchal \\ Chandramauli Basu}

General Surgery, Department of Surgery, Medical College and Hospital, Kamothe, Navi Mumbai, India

\begin{abstract}
Leiomyoma of the uterus is the most common tumor of the female pelvis. Its occurrence in females under the age of 20 years is not frequent. Moreover, its presence in the adolescent population has not been well documented. With the advent of high frequency ultrasonography and magnetic resonance imaging it is now possible to diagnose such cases at an early stage. Asymptomatic uterine fibroids can be left untreated as long as they are monitored closely. However, larger tumors usually require surgical treatment. Medical management by prescribing gonadotropin-releasing hormone analogue has been used to suppress estrogen production, thereby reducing the size of existing myomas to make them amenable to laparoscopic surgery. Selective embolization of uterine artery has been used successfully in the treatment of uterine fibroids. We came across a similar case of a large leiomyoma in a sexually inactive adolescent girl. She presented with a lump in her abdomen and without a history of menstrual disturbances or intake of oral contraceptives.
\end{abstract}

Keywords: leiomyoma of uterus, fibroid uterus

\section{Introduction}

Uterine fibroid tumors are noncancerous growths in the uterus, frequently found in women between ages 30-45 years. They account for about one quarter of all hysterectomies performed in the United States each year. Fibroids develop from cells in the wall of the uterus. They can be sub mucosal, intramural or sub serous in location. Large uterine fibroids can cause pain, constipation, frequency of micturation and increased menstrual bleeding. These tumors can block fallopian tubes, leading to infertility. They may also cause miscarriage and premature labor. The cause of uterine fibroids is unknown, but evidence suggests that their growth is tied to estrogen. Diagnosis is made with fair accuracy by transvaginal ultrasonography or magnetic resonance imaging (MRI). Fibroid tumors that are asymptomatic can be left untreated as long as they are monitored closely. However, large uterine fibroids usually require surgical treatment.

\section{Case report}

An adolescent girl of 16 presented to us with a painless lump and distension of her abdomen. Her symptoms had been present for 10 months. There was no history of nausea, vomiting, loss of weight, or appetite. There was a history of bowel and bladder irregularity. Menarche was at age 13 years and no menstrual irregularity was reported. She denied prior sexual activity and use of hormones. There was no
Correspondence:Tanweer Karim 102, Saicharan, Apartment, Plot A 4I/42/43, Sector 23, Darave, Nerul, Navi Mumbai, India

Tel +9l 9987342687

Email karimtanweer@yahoo.co.in
Open Access Surgery 2010:3 13-15

(C) 2010 Karim et al, publisher and licensee Dove Medical Press Ltd. This is an Open Access article which permits unrestricted noncommercial use, provided the original work is properly cited. 
history of similar problems in her family. Her past medical and surgical history was not significant. On abdominal examination there was an intra-abdominal lump occupying hypogastrium and the umbilical region extending into iliac and lumbar area bilaterally. It was possible to move it horizontally, but no movement was possible in the craniocaudal direction. It was firm and nontender, and palpable per rectal and per vaginal examination. External genitalia were normal. Ultrasonography (USG) abdomen and transvaginal USG showed soft tissue mass arising from the uterus, $25 \times 15 \times 10 \mathrm{~cm}^{3}$ in dimension, without necrosis or calcification. The urine human chorionic gonadotropin (hCG) was normal. On laparotomy a pedunculated fibroid was arising from the fundus of the uterus and adhered to the sacrum, restricting its mobility and occupying the pelvis completely (Figure 1). Both ovaries were normal in size and texture. When frozen, cell section showed benign cells. A myomectomy was completed and the myometrium was then closed in layers. The abdomen was closed after inserting a pelvic drain. The removed specimen was $3.2 \mathrm{~kg}$ in weight and dimensions were $25 \times 15 \times 10 \mathrm{~cm}^{3}$ (See Figure 1). The postoperative period was uneventful. Subsequent histopathological examination revealed it as a benign fibroid of the uterus.

\section{Discussion}

Leiomyoma of the uterus is the most common tumor of the female pelvis. They are benign and account for the most common indication for hysterectomy. ${ }^{1}$ They are more common in African American females, four times more common than Caucasians. ${ }^{2}$ Although the exact etiology is unclear, hormonal stimulation by estrogen, and possibly progesterone,

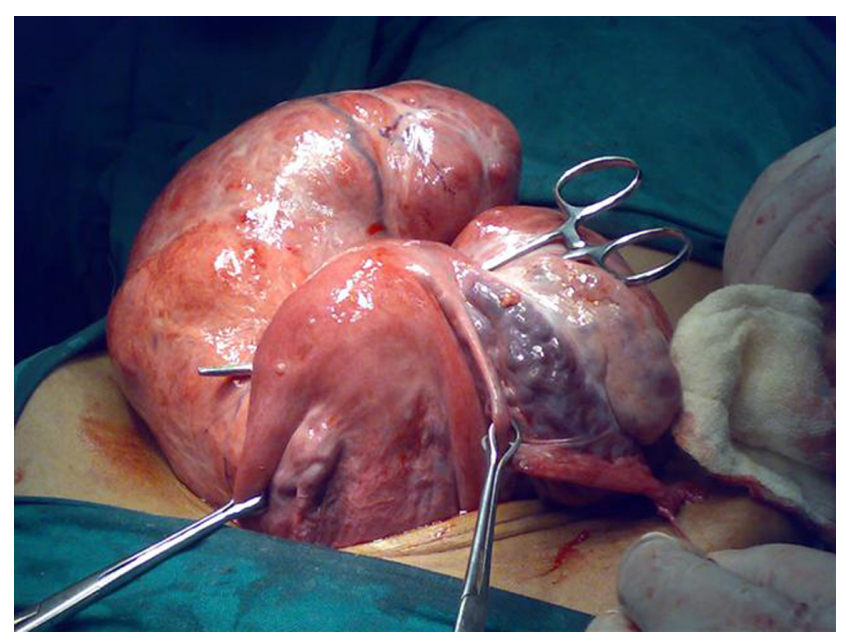

Figure I Fibroid uterus. has been suggested as a possible cause. ${ }^{1,2}$ They are present in approximately one-third of reproductive-age women; their occurrence in females under the age of 20 years is rare. ${ }^{3}$

The first case of uterine myoma in a 13-year-old girl was reported in 1969 by Wisot and colleagues, in which a myomectomy was performed because of profuse bleeding. ${ }^{4}$ Since then there are other reports of cases in which 15-year-old girls had myoma, presented with heavy menstruation, pain and uremia. There are reported cases of uterine sarcoma in this age group also. ${ }^{5-7}$ Therefore, when a pelvic mass in this age group is discovered, careful examination and radiographic imaging are imperative to arrive at the correct diagnosis.

Ultrasound is usually the initial screening tool for myomas. Since the advent of MRI, the precision for identification, number, and location of these tumors, as well as differentiation from an adnexal mass, is greatly enhanced, and in questionable cases it has been judged to be superior to USG. This is especially important when considering myomectomy in patients for whom fertility is an issue. In a study of adenomyosis by Chopra and colleagues, it has been reported that for diagnostic accuracy USG and MRI are 73\% and 100\% accurate, respectively. ${ }^{8}$ However, in the vast majority of cases transvaginal USG is all that is needed to confirm a diagnosis of uterine myoma.

Computed tomography (CT) scan has also been used as a tool to diagnose uterine fibroids. Now its role is very much limited to cases of fibroids with complications such as necrosis and malignant transformation. Appropriate counseling and possible myomectomy are recommended in symptomatic patients as well as those with large, asymptomatic tumors, in an effort to preserve fertility in this young age group. Most of these reported cases had normal obstetric history following myomectomy. Medical management by prescribing gonadotropin-releasing hormone $(\mathrm{GnRH})$ analogue has been used to suppress estrogen production, thereby reducing the size of existing myomas to make it amenable to laparoscopic surgery. ${ }^{9}$ Recently, selective uterine artery embolization has been used successfully to treat uterine myomas. One percent of patients required hysterectomy due to post embolization infection. ${ }^{10}$

\section{Disclosures}

The authors report no conflicts of interest in this work.

\section{References}

1. Van Voorhis BJ, Romitti PA, Jones MP. Family history as a risk factor for development of uterine leiomyomas: result of a pilot study. J Reprod Med. 2002;47:663-669. 
2. Faerstein E, Szklo M, Rosenshein N. Risk factors of uterine leiomyoma: A practice-based case-control study. African-American heritage, reproductive history, body size, and smoking. Am J Epidemiol. 2001;153:1-10.

3. Fields KR, Neinstein LS. Uterine myomas in adolescents: Case reports and a review of the literature. J Pediatr Adolesc Gynecol. 1996;9:195-198.

4. Wisot AL, Neimand KM, Rosenthal AH. Symptomatic myoma in a 13-year-old girl. Am J Obstet Gynecol. 1984;105:639-641.

5. Augensen K. Uterine myoma in a 15-year-old girl. Acta Obstet Gynecol Scand. 1981;60:591.

6. Bekker G, Gavrilescu T, Rickets-Holcomb L, et al. Symptomatic fibroid uterus in a 15-year-old girl. Int Surg. 2001;89:80-82.
7. Heimer G, Axelsson O, Johnson P. Uterine myoma causing uremia in a 15-year-old girl. Gynecol Obstet Invest. 1991;32:247-248.

8. Chopra S, Lev-Toaff AS, Ors F, Bergin D. Adenomyosis: common and uncommon manifestations on sonography and magnetic resonance imaging. J Ultrasound Med. 2006;25(5):617-627.

9. Stadsvold JL, Molpus KL, Baker JJ, Michael K, Remmenga SW. Conservative management of a myxoid endometrial stromal sarcoma in a 16-year-old nulliparous woman. Gynecol Oncol. 2005;99:243-245.

10. Hughes JL, Reidy JF. Imaging and treatment of uterine fibroids including the role of uterine artery embolisation. Imaging. 2003;15:79-88.
Open Access Surgery

\section{Publish your work in this journal}

Open Access Surgery is an international, peer-reviewed, open access journal that focuses on all aspects of surgical procedures and interventions. Patient care around the peri-operative period and patient outcomes post surgery are key topics. All grades of surgery from minor cosmetic interventions to major surgical procedures are covered. Novel techniques

Submit your manuscript here: http://www.dovepress.com/open-access-surgery-journal

\section{Dovepress}

and the utilization of new instruments and materials, including implants and prostheses that optimize outcomes constitute major areas of interest. The manuscript management system is completely online and includes a very quick and fair peer-review system. Visit http://www.dovepress.com/ testimonials.php to read real quotes from published authors. 